\title{
METABOLISM OF SCURVY IN AN ADULT *
}

\author{
LOUIS BAUMANN, M.D., AND C. P. HOWARD, M.D. \\ IOWA CITY, IA.
}

\section{INTRODUCTION}

This study was undertaken for two reasons. First, we wished to determine whether it were possible to make an accurate study of the metabolism of a rational bed patient in the hospital ward available to us, without the assistance of a special nurse. Second, to determine whether or not a study of the mineral exchange would yield any information of value concerning scurvy, a disease which may be eventually regarded as a disturbance of metabolism.

Our first question can be answered in the affirmative. If an intelligent ward nurse, an interested intern and the usual hospital facilities are available, a metabolic experiment such as the one described by us, is possible.

The methods employed were for the most part tested on standard solutions and modified when necessary to meet experimental conditions and increase their accuracy.

\section{LITERATURE}

An exhaustive study of the Index Medicus and Surgeon General's Catalogue as well as the special Centralblätter for biochemistry, medicine and pediatrics, yielded little or no information of value. Most of the literature on this subject deals with the much mooted etiological question but has no bearing on our paper. Except for various contradictory statements by the older writers as to the commoner mineral and organic constituents of the urine, nothing of any moment could be found. Garrod ${ }^{1}$ in 1848 found that antiscorbutic articles of food were richer in potassium than ordinary food material and that the urine and blood of scurvy patients contained a diminished amount of potassium salts.

Ralfe $^{2}$ shortly after, though confirming the potassium deficiency in the scorbutic's urine, refuted this potassium food deficiency hypothesis by administering potassium nitrate to scurvy patients without beneficial results. This author's study is spoiled for our purposes owing to the fact that the food was not measured or analyzed. He, however, studied

*From the wards of the Montreal General Hospital and the Medical Chemical Laboratory, McGill University, Montreal.

* Manuscript submitted for publication March 11, 1912.

1. Garrod, A. B.: Month. Jour. Med. Sc. (Lond. \& Edinb.), 1848, viii, 457.

2. Ralfe, C. H.: Lancet, London, 1877 , i, 868; ii, 81 . 
in the urine the free acidity, urea, uric acid, and the inorganic constituents, chlorin, sulphuric acid, calcium and magnesium phosphates, potassium and sodium phosphates, and potassium and sodium. Ralfe found in the urine of scurvy patients that there is an increase of uric acid, a diminution of the total acidity and a reduction of the alkaline phosphates.

Buzzard $^{3}$ tried to overcome Ralfe's objection by stating that it was the organic salts of potash that possessed the antiscorbutic powers. More recently Hutchison ${ }^{4}$ has accepted Buzzard's view and found that a sterilized dialysate of orange juice and to a less degree a solution of malate or tartrate or citrate of potassium had a curative effect. Litten ${ }^{5}$ writes that the results of the potassium analyses of the urine are very contradictory; further, that phosphoric anhydrid is increased and that beyond a doubt the uric acid content is very high at the height of the disease but diminishes rapidly with the convalescence.

Wright ${ }^{6}$ maintained that the exclusive feeding with certain foods (as oats, barley, fresh and salt meats) which after incineration left an acid ash, were responsible for the production of scurvy and accordingly regarded it as an acid intoxication.

Holst, ${ }^{11}$ Frölich., ${ }^{7,9}$ and Fürst' ${ }^{10}$ disproved Wright's contention by producing scurvy in guinea-pigs with foods (as peas, almonds, and lentils) yielding an alkaline ash. The disease picture both macroscopically and microscopically revealed the characteristic changes of the osseous system found in scurvy-rickets of children. Mixtures of nine varieties of dried vegetables with an alkaline ash caused scurvy in from twenty-seven to thirty-one days. In the fresh state these vegetables possessed antiscorbutic properties. This experimental scurvy could be cured by the administration of barley, peas and lentils which had previously been allowed to sprout. Further, raw milk lessened the scurvy produced in guinea-pigs by the exclusive feeding with oats; this antiscorbutic quality of the milk was destroyed by heating to $100 \mathrm{C}$. for ten minutes. The authors therefore concluded that scurvy is due to an absence in the food of some constituent possibly of the nature of an enzyme.

Nowhere in the literature could we find an accurate study of the mineral metabolism in a case of adult or infantile scurvy. Hence we believe that our careful study may prove of some use and stimulate future investigation.

3. Buzzard, Thos.: Reynold's System of Medicine (London), Ed. 3, 1876, i, 765.

4. Hutchison, Robt.: Lancet, London, 1904, i, 1253.

5. Litten, M.: Nothnagel's Handbuch der Spec. Path. u. Therap., 1901, viii, 3. 277 .
6. Wright, A. E.: Lancet, London, 1908, ii, 725 and 1365.
7. Holst and Frölich: Biochem. Centralblatt, 1907, vi, 857.
8. Holst and Frölich: Norsk. Mag. f. Lägev., 1910, 5 R. viii, 209.
9. Frölich: Zentralbl. f. Biochem. u. Biophysik., 1910, x, 722.
10. Fürst: Zentralbl. f. Biochem. u. Biophysik., 1910, x, 3098.
11. Folst: Zentralbl. f. Biochem. u. Biophysik., 1910, x, 3096. 


\section{CLINICAL HISTORY}

M. M., aged 38. Laborer; Austrian Pole; admitted to Dr. H. A. Lafleur's service in the Montreal General Hospital on July 2, 1909.

Entrance Complaint.—"Sore Knee."

Family History.-Negative.

Personal History.-The patient was born in Austrian Poland, where he had lived until 1907, when he emigrated to Canada. He had always enjoyed good health and denied all acute infections as scarlet, typhoid, and rheumatic fevers, syphilis or purpura. For some months prior to his illness he had been working as a day laborer in Blue Bonnets, a little village on the outskirts of Montreal. He lived in a shanty with twenty-one other men in one sleeping room, under poor hygienic conditions. Their food consisted of fresh meat and beans, but very little if ang fresh vegetables; very little salt pork or fish were used. As far as the patient knew, none of his companions had sore gums or spots on the skin similar to his.

Present Illness began one month before admission when he had pain, swelling and limitation of movement of the left knee joint which he assigned at first to an injury received three months before, which, however, had not laid him up at that time. Coincident with the swelling of the knee he noticed for the first time spots on the skin of the thighs as well as soreness of the gums. There were no hemorrhages from the mucous membranes or other joint symptoms.

Physical Examination July 3, 1909, revealed a fairly well-nourished though somewhat anemic man of about stated age. Numerous petechiæ were seen around the hair follicles of both extremities, especially on their anterior surface. There was a large subcutaneous purplish ecchymosis behind the lower third of the right thigh and knee joint which on palpation was markedly indurated and slightly tender. The left knee joint was much swollen, painful on movement and of a purplish red color. A skiagram was negative for periosteal or other bone lesions of that locality. On the outer side of the right elbow joint was a small subcutaneous ecchymosis. In addition there were numerous small superficial ecchymoses, some quite fresh, over the posterior and inner surfaces of the left thigh. On the trunk were a few acneiform papules. Just below and to the outer side of the left elbow joint was a subcutaneous nodule the size of a large bean. The gums, which bled very easily, were of a dull purplish hue and very spongy: they protruded slightly over the teeth, between which they showed the usual tongue-like projections. There were two or three dark greenish-black patches of necrosis on the buccal service of the gums. The breath was distinctly fetid. The teeth were carious but not loose. The lymphatic glands were normal except for a slight enlargement of both axillary groups.

The other viscera were normal.

There was a moderate secondary anemia (Hb., 40 per cent., Sahli; R. B. C., $2,690,000)$ while the leukocytes were below normal $(4,480)$.

The temperature ranged between 97.8 and $100 \mathrm{~F}$., and the pulse between 80 and 90 per minute. He weighed on admission $1371 / 2$ pounds. The urine was yellow in color, acld in reaction with a specific gravity of 1,008, and contained neither albumen, sugar nor pathological sediment.

Treatment.-On July 4 the patient was placed on a special diet for purposes of study. One week later orange juice was added to the diet.

The metabolism experiment ceased July 17 when he was found to weigh $132 \%$ pounds. After this he was given a general ward diet with abundant green vegetables, lemons and oranges. The improvement in his general condition was rapid. The gums became smaller and of a more healthy color. The brawny induration of the right thigh cleared up and the knee joint could be easily flexed and extended. The purpuric spots became smaller and were represented for the most part by brownish pigmented areas. On July 23, after being up and about the ward for two days, he insisted on going home and was, consequently, discharged. 


\section{CHEMICAL METHODS}

Owing to the semiliquid consistency of the stools, it was impossible to accurately separate the feces by means of charcoal, carmin, etc. For this reason the experiment was divided into four periods. The feces of the first day of the fore-period and of the first two days of the main period of the experiment were collected and analyzed separately. During the first and second periods, lasting one and five days, respectively, the patient received the following diet, qualitatively similar to that recommended by Folin. ${ }^{12}$ (This diet more than fulfils the requirements of the average man of 70 kilos as far as protein and calories are concerned.)

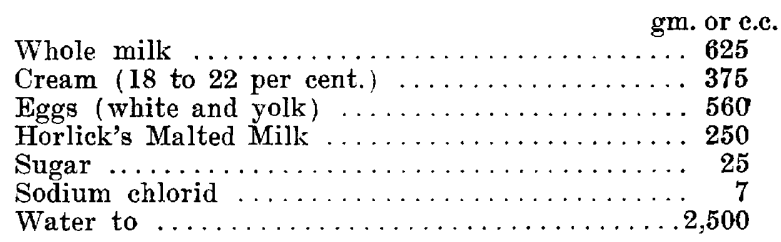

The mixture was freshly prepared and 2,000 c.c. administered each day. The balance was accurately measured and preserved under 20 c.c. toluol in bottles with well-fitting ground-glass stoppers. These were kept constantly in a refrigerator. During the third and fourth periods, lasting two and five days, respectively, the same diet was administered, except that 250 c.c. of the water was replaced by 250 c.c. of orange juice. A sample of each day's food was analyzed separately.

The urine was collected in the ordinary hospital urinal and transferred quantitatively by means of a known quantity of distilled water into a 2.5-liter glass-stoppered bottle and preserved in the refrigerator under toluol. At the end of two years the urine was acid and free from bacterial growth. On analysis the urine was found to contain, in addition to a rather bulky sediment of urates, a relatively heavy one of uric acid. In order to obtain a clear solution, we proceeded as follows: The bottle was thoroughly shaken and about 500 c.c. of the urine quickly transferred into a dry round-bottomed flask, the neck of which was drawn out into a tube about $\% 0 \mathrm{~cm}$. long and 12 to $13 \mathrm{~mm}$. in diameter. This tube was surrounded by a glass condensing jacket and cooled with running water. The urine could now be heated to boiling without loss of water, which was necessary at times in order to obtain a clear solution, and even then a few crystals of uric acid would remain undissolved. The urine in the flask was afterward rapidly cooled to $15 \mathrm{C}$. and transferred to a dry Jena. Erlenmeyer flask and the required volume pipetted.

The total nitrogen, the ammonia and the total acidity were determined in the freshly collected and unheated urine at the outset of the experiment.

12. Folin, Otto: Am. Jour. Physiol., 1905, xiii, 45. 
The mineral ingredients were analyzed subsequently at our leisure. We would here advise that for the preservation of the urine for potassium and sodium analyses, bottles made of Jena or other resistant glass be used.

The stools for each period were transferred quantitatively by means of distilled water into a carefully tared desiccator and dried to constant weight in vacuo at 45 to $55 \mathrm{C}$. The desiccator was placed in a waterbath and connected by means of a curved glass tube with a 2-liter distilling flask, the stem of which entered a suction flask containing a little $\mathrm{N} / 10 \mathrm{H}_{2} \mathrm{SO}_{4}$ solution and a drop of alizarin red. The diminished pressure was obtained by means of an ordinary water suction apparatus and the condensation by means of running water.

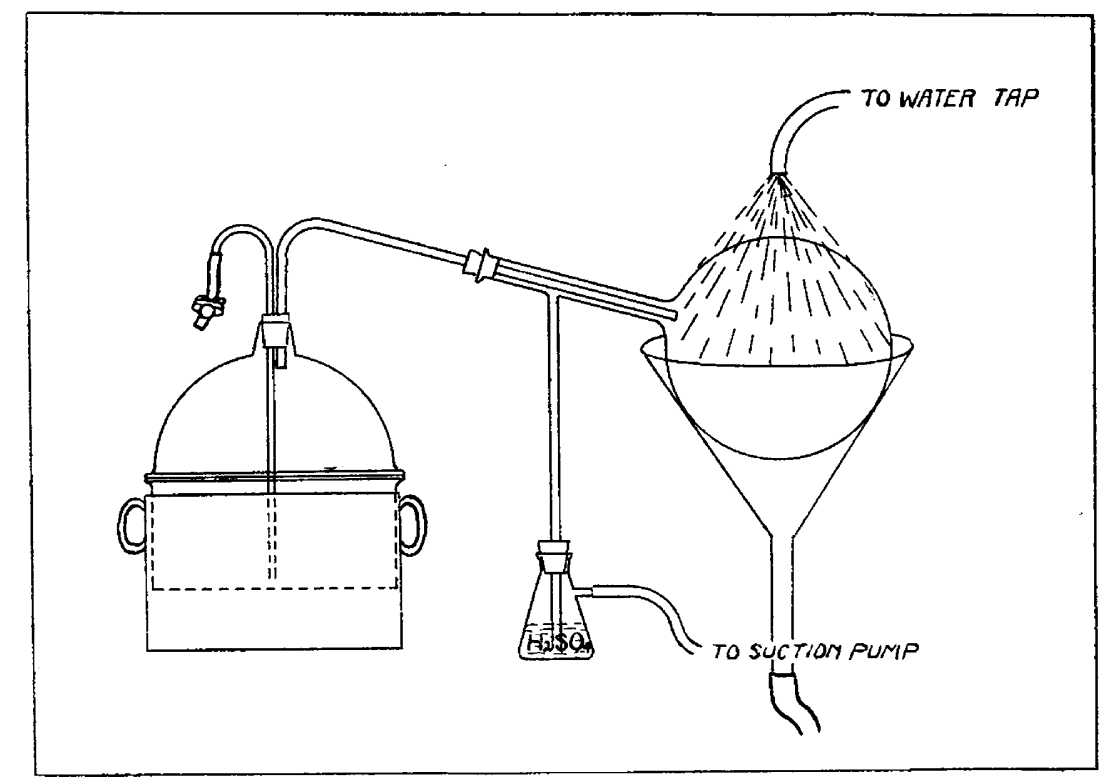

Diagram of desiccator descrioed in text

In this way the feces were dried to constant weight in twelve to thirty-six hours, depending on the quantity. On the average, 5.7 per cent. of the total nitrogen present in the feces was found in the clear distillate. Frothing of the feces was prevented by aeration through the small tube and a few drops of petroleum. The total quantity of the dried feces was obtained by subtracting the weight of the empty desiccator from the desiccator and the dried feces. The bulk of the feces was removed with a spatula, ground in a mortar and preserved in bottles hermetically sealed with paraffin until analyzed. It was not necessary to pulverize the feces, as concordant duplicate analyses were obtained with samples containing particles the size of a pea. For example, the following results for nitrogen and calcium were obtained. 


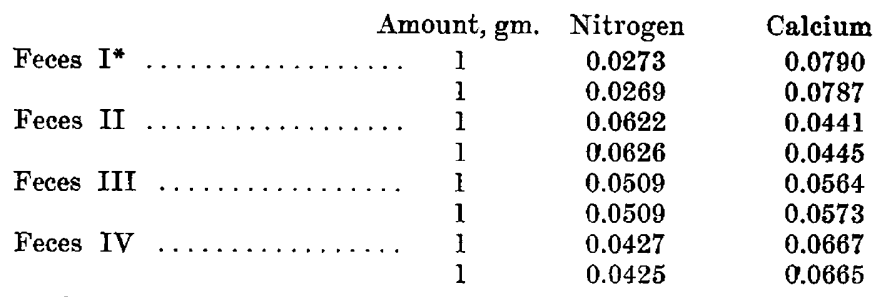

*The analyses wern carried out in duplicate.

The homogeneous nature of the liquid food mixture employed was determined by repeated analyses of definite volumes.

Analytical Methods.-All analyses were carried out in duplicate and rejected unless the variation between the two analyses was well within the experimental error. The average of the duplicate analyses was selected as the basis for calculation. The maximum variation for each series is given in its proper place. It was computed by selecting the greatest variation between the duplicates of a series and this error calculated for 100 c.c. of urine or food or 100 grams of feces.

1. Urine-The nitrogen was determined according to Kjeldahl, 10 c.c. being used in duplicate. Sodium alizarinsulfonate was used as indicator. The maximum variation for 100 c.c. urine was 0.004 nitrogen.

The ammonia was determined according to Folin, ${ }^{13} 25$ c.c. being used and the air passed through the cylinder over night. The indicator used was sodium alizarinsulfonate. The maximum variation between the duplicates for 100 c.c. of urine was $0.003 \mathrm{NH}_{3}$.

The total acidity was estimated according to Folin. ${ }^{14}$ The number of cubic centimeters of $\mathrm{N} / 10 \mathrm{Na}(\mathrm{OH})$ required to neutralize the total quantity of the urine was calculated. The exact end-point in this titration could only be accurately determined after a good deal of experience, the yellow color of the urine obscuring the indicator, phenolphthalein. The maximum variation was 0.8 c.c. $\mathrm{N} / 10 \mathrm{Na}(\mathrm{OH})$ for 100 c.c. urine.

The total sulphur was determined according to Benedict ${ }^{15}$ with 10 c.c. of urine. This method was found to be more accurate and rapid than the sodium peroxid method used by Folin. ${ }^{16}$ The following consecutive analyses are illustrative:

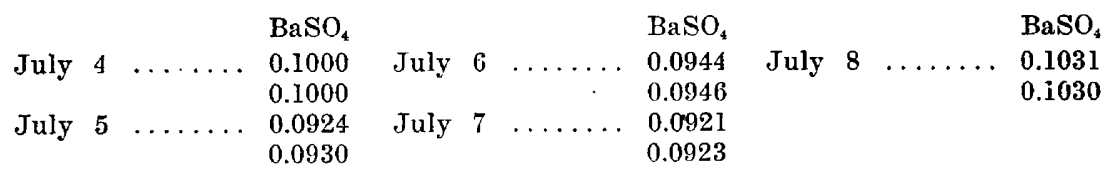

13. Folin, Otto: Z. f. Physiol. Chemie, 1902, xxxvii, 161; P. Schaffer, Amer. J. Phys., 1903, 8, 330.

14. Folin, Otto: Am. Jour. Physiol., 1903, ix, 265.

15. Benedict, S. R.: Jour. Biol. Chem., 1909, vi, 363.

16. Folin, Otto: Jour. Biol. Chem., 1906, i, 131. 
The maximum error in duplicate determination was less than 0.001 grams sulphur for 100 c.c. urine. We did not therefore find it necessary to use the modification suggested by Denis. ${ }^{17}$

Chlorin was estimated according to Clarke's ${ }^{18}$ modification of Dehn's method, 10 c.c. of urine being used in duplicate. The maximum error was $0.004 \mathrm{gm} . \mathrm{Cl}$ in 100 c.c. of urine.

Total Phosphorus.-The urine was first ashed according to Neumann in Kjeldahl flasks of Jena glass. Five c.c. of concentrated $\mathrm{H}_{2} \mathrm{SO}_{4}$ was added to 100 c.c. urine and complete destruction of the organic matter obtained by the gradual addition of concentrated nitric acid. The ash and sulphuric acid were transferred to a measuring flask and diluted to 250 c.c. This solution served for the determination of the total phosphorus as well as the potassium and sodium. Twenty-five cubic centimeters of this solution, corresponding to 10 c.c. of urine, were analyzed according to the volumetric method of Neumann ${ }^{19}$ for phosphorus. In order to obtain a coarsely granular precipitate of the ammonio-phosphomolybdate which might be easily washed free of acid and filtered, we proceeded as follows:

To 25 c.c. of the Neumann ash solution in a Jena Erlenmeyer flask of 400 c.c. capacity, 125 c.c. of water, 50 c.c. of 50 per cent. ammonium nitrate solution, 3 c.c. of concentrated sulphuric acid and 1 c.c. of concentrated nitric acid were added. The mixture was then heated until bubbles began to appear and then precipitated with 40 c.c. of 10 per cent. ammonium molybdate solution. The flask was then shaken until precipitation was complete (about one minute) and allowed to stand for ten minutes, after which it was decanted through Gooch crucibles in the manner suggested by Bayliss and Plimmer. ${ }^{20}$

As a rule after four washings the precipitate was free from acid and could then be decomposed and titrated in the usual manner. In this way the total phosphorus of the urine, feces and food could be rapidly and accurately determined. As many as three duplicate determinations were carried out on the ash solution in ten hours. The following five consecutive duplicate analyses illustrate the accuracy of this method:

\begin{tabular}{|c|c|c|c|c|c|}
\hline July 12 & $\begin{array}{c}\mathrm{P}_{2} \mathrm{O}_{5} \\
0.0398 \\
0.0400\end{array}$ & & $\begin{array}{c}\mathrm{P}_{2} \mathrm{O}_{5} \\
0.0408 \\
0.0408\end{array}$ & July 16 & $\begin{array}{c}\mathrm{P}_{2} \mathrm{O}_{5} \\
0.0398 \\
0.0395\end{array}$ \\
\hline July 13 & $\begin{array}{l}0.0406 \\
0.0407\end{array}$ & July 15 & $\begin{array}{l}0.0414 \\
0.0420\end{array}$ & & \\
\hline
\end{tabular}

The maximum error was $0.005 \mathrm{gm}$. phosphorus for 100 c.c. urine.

Sodium and Potassium.-These were determined on the Neumann ash solution mentioned above. Twenty-five c.c. of the solution (equivalent to 10 c.c. urine) was evaporated in a platinum dish and the sulphuric acid

17. Denis, W.: Jour. Biol. Chem., 1910, viii, 401.

18. Clark, S.: Hawk's Practical Physiol. Chem., Ed. 3, 1910, p. 388.

19. Neumann, A.: Ztschr. f. Physiol. Chem., 1902-3, xxxvii, 129; 1904-5, xliii, 35.

20. Bayliss and Plimmer: Jour. Physiol., 1905-6, xxxiii, 441. 
completely volatilized. The residue was dissolved in a little distilled water, transferred to a Jena Erlenmeyer flask to which was added 5 c.c. of concentrated $\mathrm{HCl}$ and 100 c.c. of water; this solution was now boiled and the $\mathrm{SO}_{4}$ ions were precipitated by the gradual addition of barium chlorid through the Folin automatic dropper. ${ }^{21}$ When cool the barium sulphate was filtered off through an ashless filter into a platinum dish; the precipitate was now washed thoroughly and the washings and filtrate evaporated to dryness on the water-bath to remove the bulk of the hydrochloric acid. The residue was again dissolved in water, transferred to a Jena Erlenmeyer flask, to which 100 c.c. of water was added, then heated to boiling and precipitated by the gradual addition (drop method) of 20 c.c. of a half saturated solution of chemically pure barium hydrate obtained by double recrystallization. When cold it was filtered and washed thoroughly. The filtrate and washings were treated with an ammoniacal solution of ammonium carbonate (made by passing dry $\mathrm{CO}_{2}$ into a 15 per cent. solution of $\mathrm{NH}_{3}$ ) until no further precipitation occurred. After two hours the precipitate was then filtered off, washed thoroughly and the filtrate and washings evaporated carefully to dryness on the water-bath, avoiding a too rapid decomposition of the ammonium carbonate. The residue was again treated with about 10 c.c. of the ammoniacal ammonium carbonate solution for two hours, any resulting precipitate filtered and the filtrate and washings again evaporated to dryness. The residue was taken up in water, transferred to a weighed platinum crucible, evaporated to dryness on the water-bath and the ammonium salts volatilized. When the weight of the crucible was constant, the weight of the chlorids of the potassium and sodium was noted; they were then dissolved in a little water and filtered, as a small amount of insoluble residue was always present. The filter and residue were washed thoroughly, dried and incinerated and the weight of the ash deducted from the weight of the sum of the chlorids of potassium and sodium.

The potassium was determined as potassium platinic chlorid $\left(\mathrm{K}_{\mathbf{2}} \mathrm{PtCl}_{6}\right)$. In this way acceptable results were obtained with a standard solution containing potassium and sodium chlorid, acid potassium phosphate, sulphuric acid, calcium carbonate and magnesium sulphate in about the proportions in which they occur in the ash solution to be analyzed.

\begin{tabular}{|c|c|c|c|}
\hline \multirow{3}{*}{ Solution } & & $\mathrm{NaCl}$ & $\mathrm{KCl}$ \\
\hline & I contained & 0.1011 & 0.0692 \\
\hline & $\begin{array}{l}\text { found } \\
\text { found }\end{array}$ & $\begin{array}{l}0.1010 \\
0.1003\end{array}$ & $\begin{array}{l}0.0694 \\
0.0691\end{array}$ \\
\hline & found & 0.1016 & 0.0694 \\
\hline \multirow[t]{4}{*}{ Solution } & II contained & 0.0809 & 0.0553 \\
\hline & found $\ldots$ & 0.0806 & 0.0552 \\
\hline & found & 0.0814 & 0.0550 \\
\hline & found & 0.0811 & 0.0553 \\
\hline
\end{tabular}

21. Folin, Otto: Jour. Biol. Chem., 1906, i, 131. 
The maximum error for sodium was 0.005 and for potassium 0.009 for 100 c.c. of urine.

Calcium and Magnesium.-Fifty c.c. of urine were analyzed directly for calcium and magnesium according to the method of MeCrudden. ${ }^{22}$ We can fully corroborate the author's claim for the accuracy of his method. For seven consecutive duplicate analyses we obtained the following:

\begin{tabular}{|c|c|c|c|}
\hline \multirow{3}{*}{ July } & \multirow[b]{2}{*}{4} & $\mathrm{MgO}$ & $\mathrm{CaO}$ \\
\hline & & 0.0107 & 0.0117 \\
\hline & & 0.0107 & 0.0117 \\
\hline July & 5 & 0.0074 & 0.0120 \\
\hline July & 6 & $\begin{array}{l}0.0073 \\
0.0069\end{array}$ & $\begin{array}{l}0.0122 \\
0.0129\end{array}$ \\
\hline & & 0.0072 & 0.0129 \\
\hline July & 7 & 0.0069 & 0.0123 \\
\hline & & 0.0072 & 0.0125 \\
\hline July & 8 & $\begin{array}{l}0.0087 \\
0.0088\end{array}$ & $\begin{array}{l}0.0142 \\
0.0146\end{array}$ \\
\hline July & 9 & 0.0080 & 0.0146 \\
\hline July & 10 & 0.0078 & 0.0141 \\
\hline & & 0.0078 & 0.0141 \\
\hline
\end{tabular}

The Aron ${ }^{28}$ method for determining calcium as $\mathrm{CaSO}_{4}$ proved entirely unsatisfactory in our hands.

2. Food. For the total nitrogen 5 c.c. was taken in duplicate and determined by Kjeldahl's method.

For the total sulphur, 5 c.c. was also taken and determined by Benedict's method with the following results:

\begin{tabular}{|c|c|c|c|c|c|c|}
\hline July & 8 & $\begin{array}{r}\mathrm{BaSO}_{4}, \mathbf{g m} \\
\ldots \ldots 0.0228\end{array}$ & July 10 & $\begin{array}{l}\mathrm{BaSO}_{4}, \mathrm{gm} . \\
\ldots \ldots .0216\end{array}$ & July 12 & $\begin{array}{l}\mathrm{BaSO}_{4}, \mathbf{g m} . \\
\ldots .00206\end{array}$ \\
\hline July & 9 & $\begin{array}{l}0.0228 \\
0.0226 \\
0.0222\end{array}$ & July 11 & $\begin{array}{r}0.0220 \\
. \quad 0.0224 \\
0.0228\end{array}$ & & \\
\hline
\end{tabular}

The maximum error was $0.003 \mathrm{gm}$. sulphur for 100 c.c. of food.

The total chlorin was determined in duplicate, using 5 c.c. of food. The sodium peroxid method was used and chlorin weighed as silver chlorid $(\mathrm{AgCl})$. The maximum error was $0.006 \mathrm{gm}$. of chlorin for 100 c.c. of food.

The phosphorus was determined in 100 c.c. of the food by ashing according to Neumann and the ash and sulphuric acid diluted to 250 c.c. Of this solution 25 c.c. in duplicate were analyzed in the manner above described. The maximum error was $0.003 \mathrm{gm}$. of phosphorus for 100 c.c. of food.

The sodium and potassium were determined in the same manner as in the urine, using 25 c.c. of the ash solution or 10 c.c. of food in duplicate. The following five consecutive results were obtained:

22. McCrudden, F.: Jour. Biol. Chem., 1910, vii, 83.

23. Aron, H.: Biochem. Ztschr., 1907, iv, 268. 


\begin{tabular}{|c|c|c|}
\hline \multirow{3}{*}{ July 4} & $\mathrm{NaCl}$, gm. & $\mathrm{KCl}, \mathrm{gm}$. \\
\hline & 0.0530 & 0.0351 \\
\hline & 0.0529 & 0.0352 \\
\hline \multirow[t]{2}{*}{ July } & 0.0499 & 0.0359 \\
\hline & 0.0497 & 0.0367 \\
\hline \multirow[t]{2}{*}{ July } & 0.0529 & 0.0424 \\
\hline & 0.0530 & 0.0429 \\
\hline \multirow[t]{2}{*}{ July 7} & 0.0512 & 0.0368 \\
\hline & 0.0519 & 0.0361 \\
\hline \multirow[t]{2}{*}{ July 8} & 0.0450 & 0.0360 \\
\hline & 0.0456 & 0.0369 \\
\hline
\end{tabular}

The maximum error was $0.0027 \mathrm{gm}$. for sodium and $0.005 \% \mathrm{gm}$. for potassium for 100 c.c. of food.

The calcium and magnesium in the food were determined as follows: Twenty-five c.c. of the food was allowed to dry on a platinum dish on the water-bath for from twelve to fifteen hours; it was then gradually charred and extracted with dilute hydrochloric acid. The residue was now gradually incinerated until a grayish white ash with a few black particles remained; to this the hydrochloric acid extract was added and the whole evaporated and allowed to dry in an oven at $110 \mathrm{C}$. for two hours to render any silicic acid insoluble. The ash was then dissolved in about 100 c.c. of water containing 3 c.c. concentrated hydrochloric acid, filtered and analyzed for calcium and magnesium by McCrudden's method. The maximum error was $0.0017 \mathrm{gm}$. calcium and $0.0007 \mathrm{gm}$. magnesium for 100 c.c. of food.

3. Feces. Nitrogen was determined in 10 c.c. of the distillate obtained from the feces while drying in vacuo, as well as in $1 \mathrm{gm}$. of the dry feces, the maximum error for $100 \mathrm{gm}$. of the dried feces being $0.040 \mathrm{gm}$. of nitrogen.

Sulphur.-From 0.5 to $1.5 \mathrm{gm}$. of the dried feces was treated with 20 c.c. of fuming nitric acid in a Kjeldahl flask and a small amount of heat applied until the solid matter had disappeared and the brown fumes had considerably decreased. The solution was then transferred to a 100 c.c. porcelain evaporating dish, to which 20 c.c. of Benedict's solution and $2 \mathrm{gm}$. of C. P. sodium chlorid were added; the whole evaporated to as complete dryness as possible, then very gradually heated to redness, and when cold covered with a watch glass and dissolved in dilute $\mathrm{HCl}$, filtered and precipitated in the usual manner. The four specimens examined by this method gave the following sulphur value for $1 \mathrm{gm}$. of dried feces:
I. $\ldots \ldots, 0.0043$
III. . . . . 0.0083
0.0044
0.0084
II. . . . . 0.0061
0.0061
IV. . . . 0.0040
0.0041

Maximum error for $100 \mathrm{gm}$. dried feces $=0.0100$ sulphur. 
The sodium chlorid was added to prevent loss by deflagration which regularly occurred in the trying out of Wolff and Osterberg's modification of Benedict's method. ${ }^{24}$

Chlorin.-From 1 to $1.5 \mathrm{gm}$. of the dried feces was weighed into a platinum dish, 25 c.c. of a 10 per cent. solution of C. P. sodium carbonate added and the whole evaporated to dryness on the water bath, then gradually incinerated, avoiding red heat. The cold ash was extracted with dilute nitric acid under a watch glass, the residue heated until white, the acid extract added and the whole evaporated to dryness, then heated to 110 for two hours, taken up in dilute nitric acid, filtered and precipitated with silver nitrate solution. When cold and the precipitate had settled, the silver chlorid was filtered through a tared Gooch crucible, dried at $120 \mathrm{C}$. and weighed. The four samples analyzed gave the following chlorin values for $1 \mathrm{gm}$. of dried feces:

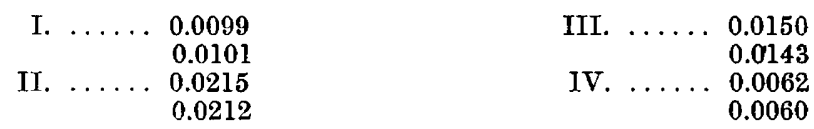

The maximum error was 0.070 chlorin for $100 \mathrm{gm}$. of the dried feces.

Phosphorus was determined according to Neumann, as in the case of the urine and food. The maximum error was $0.040 \mathrm{gm}$. of phosphorus for $100 \mathrm{gm}$. of the dried feces.

Sodium and Potassium.-The same method was used as for urine and food. The maximum error was 0.040 per $100 \mathrm{gm}$. dried feces, for sodium, and 0.050 per $100 \mathrm{gm}$. dried feces for potassium.

Calcium and Magnesium.-Dry ashing was resorted to. The subsequent steps were identical with those previously described under the calcium and magnesium determination in the food. The maximum error for calcium was 0.028 , and for magnesium, 0.024 for $100 \mathrm{gm}$. of dried feces.

\section{PROTOCOLS}

(See Protocols 1 and 2)

VI. DISCUSSION

Having selected a diet qualitatively similar to that administered by Folin ${ }^{12}$ in his metabolism experiments on the normal man, we have the opportunity of comparing our results, to some extent, with his.

Total Nitrogen. The nitrogen ingested was fairly constant throughout the experiment, the average daily intake ranging between 19.13 and $19.51 \mathrm{gm}$. The average daily excretion during the fore-period was $15.26 \mathrm{gm}$. in the urine and $4.07 \mathrm{gm}$. in the feces, i. e., about 21 per cent. of the total nitrogen excreted appeared in the feces. There was, therefore, a positive balance or nitrogen retention of $0.85 \mathrm{gm} . \mathrm{N}$ for the

24. Wolff, C., and Osterberg, Emil : Biochem. Ztschr., 1910, xxix, 429. 


\begin{tabular}{|c|c|c|c|c|c|c|c|c|c|}
\hline & & 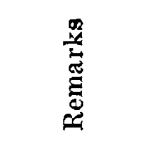 & & 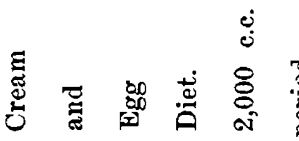 & 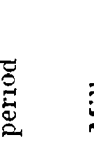 & t & & 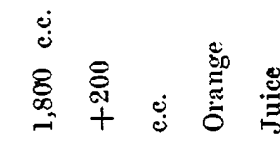 & \\
\hline & & 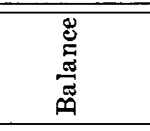 & & 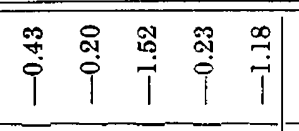 & 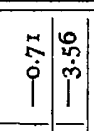 & \begin{tabular}{rr}
\multirow{4}{*}{} \\
iิ \\
1 \\
\end{tabular} & $\begin{array}{l}0 \\
\dot{1} \\
\dot{i}\end{array}$ & 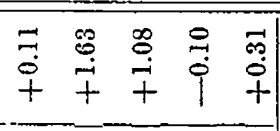 & 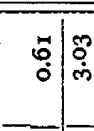 \\
\hline : & 荄 & 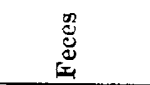 & 市 & 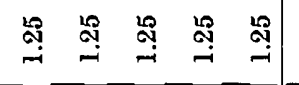 & : & : व & $\stackrel{\infty}{8}$ & 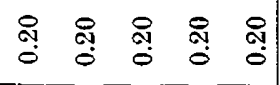 & : \\
\hline ฮี & है & 范 & 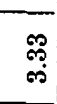 & 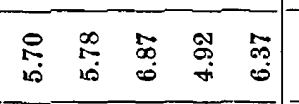 & i⿱ & 总草 & : & 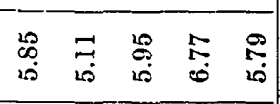 & 串 \\
\hline & & 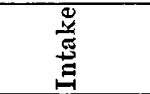 & $\overline{8}$ & 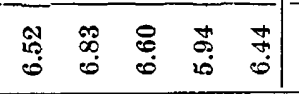 & 9. & 苛 & $\begin{array}{l}0 \\
0 \\
0 \\
0\end{array}$ & 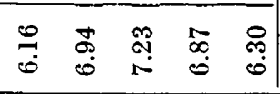 & : \\
\hline & & 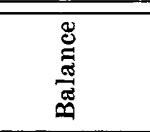 & 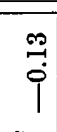 & 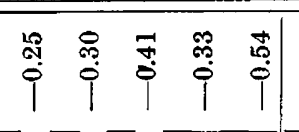 & $\begin{array}{lll}0 & 0 \\
0 & 0 \\
i & 0 \\
i\end{array}$ & 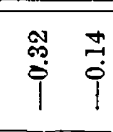 & 象产 & 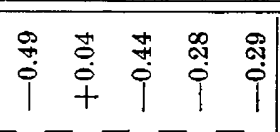 & 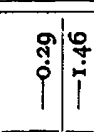 \\
\hline $\begin{array}{l}\frac{5}{2} \\
\frac{z}{2}\end{array}$ & 音 & 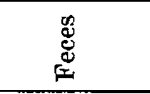 & $\frac{7}{0}$ & $\begin{array}{cccc}0 & 0 & 0 & 0 \\
0 & 0 & 0 & 0 \\
0\end{array}$ & $\stackrel{0}{0}$ & $\stackrel{0}{0}$ & : & $\begin{array}{llll}4 & \pm & \pm & \pm \\
0 & 0 & 0 & 0 \\
0\end{array}$ & 4 \\
\hline 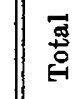 & $\bar{g}$ & 苋 & $\stackrel{9}{=}$ & 引 & 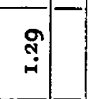 & 采 & $\stackrel{\circ}{\square}$ & 象 & 资 \\
\hline & & 总 & פֶּ & 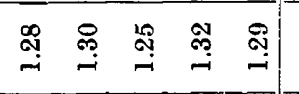 & 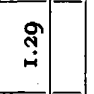 & 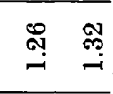 & : & 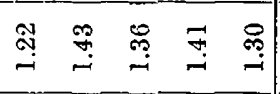 & \\
\hline & 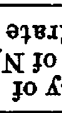 & 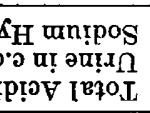 & * & 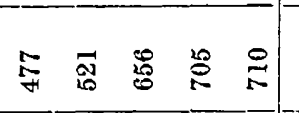 & $\begin{array}{l}\infty \\
\tilde{0} \\
0\end{array}$ & 禺象 & : & 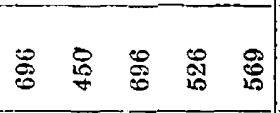 & 离 \\
\hline & 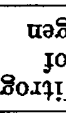 & 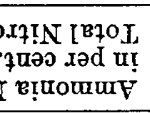 & t) & 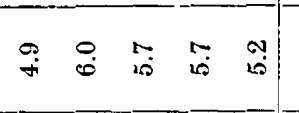 & 瓷 & $\begin{array}{lll}\infty & 0 \\
0 & 0 & 0\end{array}$ & $\stackrel{\circ}{i}$ & 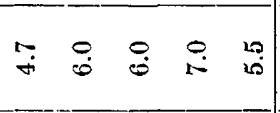 & $\begin{array}{c}0 \\
i \\
i\end{array}$ \\
\hline & $80.4 !$ & 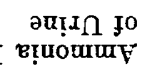 & 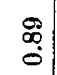 & 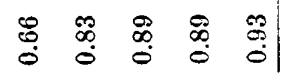 & 紫 & 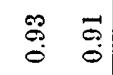 & o. & 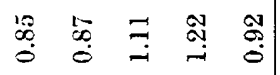 & $\stackrel{9}{\circ}$ \\
\hline
\end{tabular}

\begin{tabular}{|c|c|c|c|c|c|c|c|c|c|}
\hline & & 㚿 & 政| & 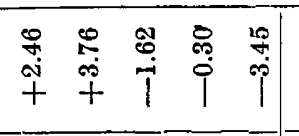 & 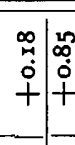 & $\begin{array}{ll}0 & 0 \\
0 & 0 \\
+ & 0 \\
+ & + \\
\end{array}$ & 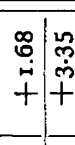 & 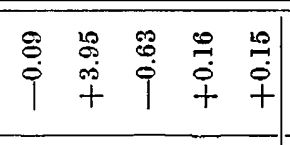 & $\begin{array}{c}0 \\
0 \\
+\end{array}$ \\
\hline & 請 & 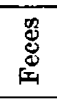 & 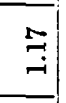 & 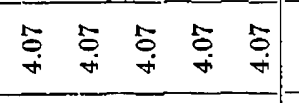 & $\stackrel{o}{+}$ & 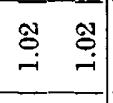 & : & 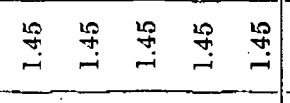 & \\
\hline & हे & 兽 & 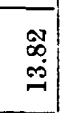 & 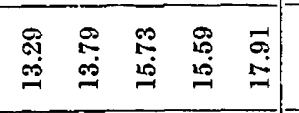 & 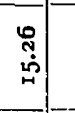 & & 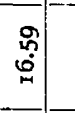 & 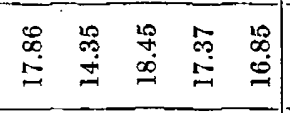 & \\
\hline & & 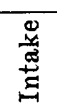 & $\begin{array}{c}\mid \\
\Phi \\
\Xi\end{array}$ & 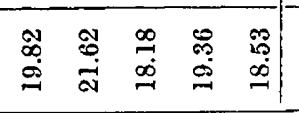 & 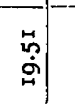 & 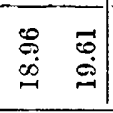 & ه్d & 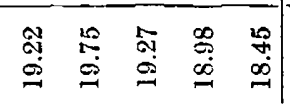 & 9 \\
\hline
\end{tabular}

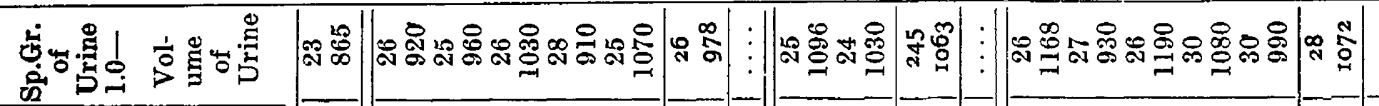




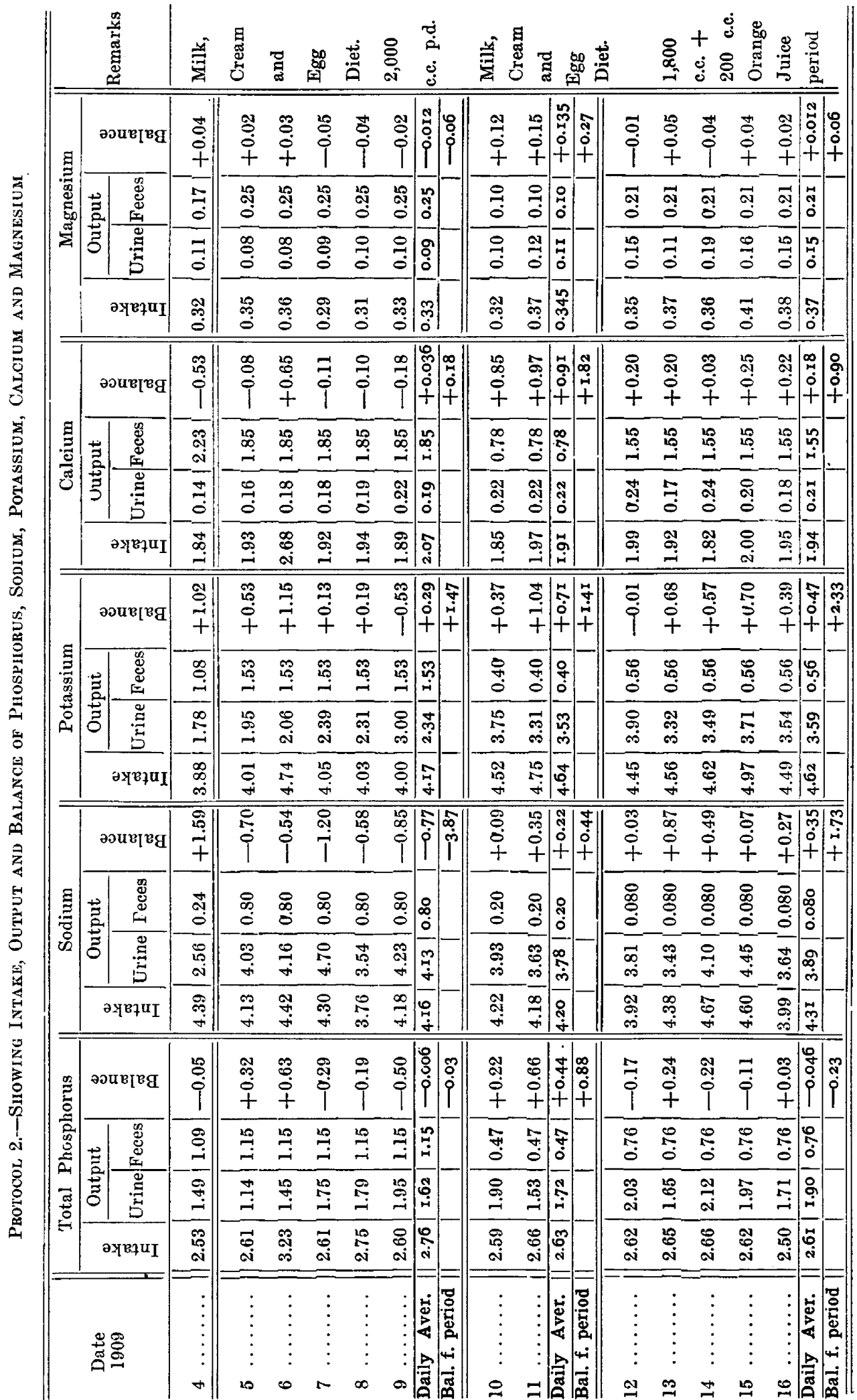


whole period. During the second part of the fruit juice period $16.98 \mathrm{gm}$. were excreted per diem in the urine, while only $1.45 \mathrm{gm}$. (or 7.8 per cent. of the total $N$ ) was present in the feces. A more marked positive balance (3.54 gm. for the period) was present after the administration of orange juice. Laurentitis has recently found, following the administration of various fruit juices, an increase in the output of both the total nitrogen and the uric acid in the urine, though no mention is made of the analyses of the feces or of the food in the abstract of his paper. In our case the urine nitrogen was increased during the fruit juice period but this was counterbalanced by the diminution of the nitrogen in the stools.

Ammonia Nitrogen. The ammonia nitrogen was slightly increased, both relatively and absolutely, but no marked difference between the periods is noticeable. The average daily ammonia-nitrogen excretion for Period II was 0.84 , for Period IV, 0.99 , as compared with Folin's average of 0.70. The ammonia coefficient was 5.5 for Period II and 5.8 for Period IV. Folin's average was 4.3. From these data one can unquestionably exclude an acidosis, as is claimed by Wright.

Total Acidity. The total acidity of the urine was somewhat lower for the fruit juice period, 587, as compared with 613.8 for the preliminary period. Folin's average was $61 \%$, and his minimum acidity, 554 .

Sulphur Metabolism. This was rather unusual. With the exception of one day, more sulphur was eliminated than ingested. At first we attributed this result to an analytical error, but further control determinations substantiated this finding. During Periods II and IV, respectively, an average daily loss of 0.36 and 0.29 occurred, leading to a minus balance of 1.83 and $1.46 \mathrm{gm}$. of sulphur for Periods II and IV, respectively, whereas the nitrogen balance was positive for both periods. The daily sulphur eliminated with the feces during Period II was $0.36 \mathrm{gm}$., or 21.9 per cent. of the total. Of the sulphur eliminated during the fruit juice period only $0.14 \mathrm{gm}$. were passed per rectum. This amounts to 8.5 per cent. of the total sulphur elimination. For want of material we were, unfortunately, unable to examine the sulphur partition.

Chlorin. The chlorin ingestion was fairly constant, $6.47 \mathrm{gm}$. during Pericd II and $6.70 \mathrm{gm}$. during Period IV being the average daily intakes. The urinary chlorin excretion was practically similar for both periods, being $5.9 \mathrm{gm}$. Folin's daily average was 6.1. Here, again, we have the better utilization during the fruit juice period for only $0.20 \mathrm{gm}$. were lost through the feces, i. e., 3.1 per cent. of the chlorin eliminated, whereas during the preliminary period $1.25 \mathrm{gm}$. or 17.4 per cent. of the total chlorin excreted was present in the feces. The average daily loss for Period II was $0.71 \mathrm{gm}$., compared with an average daily gain of $0.61 \mathrm{gm}$. for Period IV.

25. Laurenti, T.: Policlinico (Rome), 1912, xix, 525; Abstr. in Jour. Am. Med. Assn., 1912, Iviii, 452. 
Total Phosphorus. The average daily intake varied between 2.76 and $2.61 \mathrm{gm}$. The daily urinary phosphorus averaged 1.62 and $1.90 \mathrm{gm}$. for the respective periods, while $1.15 \mathrm{gm}$. was the average daily amount passed in the feces during Period II as compared with $0.76 \mathrm{gm}$. during Period IV. The balance was slightly negative throughout, 0.006 and 0.046 being the average daily losses during Periods II and IV, respectively.

Sodium. The average daily intake varied between 4.16 and $4.31 \mathrm{gm}$. for Periods II and IV, respectively. During the former 16.2 per cent., and during the latter only 1.7 per cent. was lost through the feces. During the Period II the balance was negative ( -3.87$)$, equivalent to an average daily loss of $0.77 \mathrm{gm}$. During Period IV the balance was positive $(+1.73)$, equivalent to an average daily gain of $0.35 \mathrm{gm}$.

The sodium behaved very much like the chlorin, as one would expect.

Potassium. The intake varied between the daily average of $4.1 \%$ for the preliminary period and 4.62 for the fruit juice period. A much larger percentage of the excretion occurred through the feces than was the case with sodium. During Period II, $1.53 \mathrm{gm}$. (or 39.5 per cent. of the total excretion) was the average daily amount present in the feces. During Period IV, 13.5 per cent. was lost in the feces. The balance was positive throughout, +0.29 and $+0.47 \mathrm{gm}$. being the average gains for Periods II and IV, respectively.

Calcium. Here the excretion took place largely through the intestine, as one would expect; 0.19 and $1.85 \mathrm{gm}$. was the average daily excretion in the urine and feces, respectively, during Period II, contrasted with 0.21 and 1.55 for Period IV. The balance was positive throughout but greater during Period IV (0.90), as compared with Period II (0.18).

Magnesium. Here again $0.25 \mathrm{gm}$. was excreted in the feces and 0.09 in the urine during Period II as compared with 0.21 and 0.15 during Period IV. The balance was negative during the former $(-0.06)$ and positive during the latter $(+0.06)$ periods.

VII. CONCLUSIONS

As this is the first accurate study of the metabolism of scurvy, it would be hazardous to venture any conclusion from the above figures.

In our experiment the loss of the various food constituents through the feces was less when the fruit juice was added to the diet. The total sulphur metabolism was abnormal throughout. Chlorin and sodium were retained during the fruit juice period, but excreted in excess of the intake during the preliminary period. More potassium, calcium and magnesium were retained during the fruit juice period.

If an opportunity presents, we hope to acquire additional data and possibly substantiate the above figures. Finally, we take pleasure in thanking Prof. H. A. Lafleur for his kind permission to study the case in his ward, and Prof. R. F. Ruttan for the use of the laboratory, and for various pertinent suggestions. 